https://doi.org/10.15407/ujpe64.9.837

O. CHUKOVA, S. NEDILKO

Taras Shevchenko National University of Kyiv, Faculty of Physics

(4-b, Acad. Hlushkov Ave., Kyiv 01601, Ukraine; e-mail: chukova@univ.kiev.ua)

\title{
STRUCTURE OF CENTERS OF MATRIX EMISSION OF THE UNDOPED AND RE-DOPED SCHEELITE-TYPE LEAD TUNGSTATE CRYSTALS
}

\begin{abstract}
The paper reports the investigation of a structure of luminescence spectra of $\mathrm{PbWO}_{4}(\mathrm{PWO})$ crystals. The doping of the samples with rare earth (RE) impurities is used in order to obtain more information about the composition of spectra of the PWO matrix emission and the structure of its luminescence centers. The decomposition of the emission spectra onto individual bands has shown that 5 bands contribute to the total spectra of all the undoped and $R E$-doped samples at $10 \mathrm{~K}$. The maxima of the obtained bands are 1.95, 2.2, 2.45, 2.7, and $3.0 \mathrm{eV}$. Effects of the RE-doping and the annealing on relative intensities of these bands are considered. The nature of luminescence and the structure of the centers involved in the excitation and emission processes responsible for each of the separated bands are discussed.
\end{abstract}

Keywords: luminescence center, rare earth ion, impurity, lead tungstate, matrix emission.

\section{Introduction}

The lead tungstate compounds have attracted a great attention in connection with their applications as an inorganic scintillating material [1-3]. Two decades of intensive investigations of the PWO luminescence reveal that the explanation the origins of a light emission in oxide crystals can be a complicated task [312]. At the same time, the development of models describing luminescence phenomena in wide bandgap oxides is an important scientific task, because these compounds are widely used in modern techniques with various purposes, e.g., scintillators, dosimeters, luminescence sensors, markers, probes, LED materials, laser working bodies, white light emitting diodes, solar concentrator matrices, etc. [1-3, 12-17].

Wideband luminescence emission in such oxide compounds as lead tungstate is quite complex in general, because it is formed from various bands overlapping with one another. Moreover, the bands forming the total emission spectrum can have different phys-

(C) O. CHUKOVA, S. NEDILKO, 2019

ISSN 2071-0194. Ukr. J. Phys. 2019. Vol. 64, No. 9 ical nature and can be connected with different elements of the host crystal lattice and defects. Especially, various defects play a significant role in the formation of luminescence centers (LCs) in wide bandgap oxides, where band-to-band transitions are located in the deep UV range [18-22]. Therefore, it is possible for such compounds to influence the spectral characteristics of the synthesized compounds by influencing the concentration of different types of defects in their lattices. In particular, the concentrations of oxygen vacancies and interstitial oxygen ions, which have great importance for the formation of LCs in PWO, may be varied by the doping of the matrix with some impurity ions and by the annealing. But, a realization of the predicted impact on the resulting spectra needs knowledge about the structure of LCs related to each of the bands contributing to the total spectrum.

The luminescence of the PWO compounds at low temperatures are presented by wide emission spectra covering the most of the visible range. The shapes, maxima positions, and intensities of these spectra depend on many factors such as the growth conditions, 
after-growth treatment, compositions and quality of reagents, presence of modifying impurities, and even the mechanical treatment of single crystal surfaces and the experiment conditions, e.g., the widths of optical slits [23-25]. Such behavior of the PWO emission is a result of the variations of relative contributions of several bands to the total spectrum. Those bands are characterized by a significant overlapping, and their separation is a very difficult task. Investigators of the PWO crystals have common view about the contributions of the blue band near 400-430 nm (3.1-2.9 eV), one or two bands in the green range near 460-520 nm $(2.7-2.4 \mathrm{eV})$, and two weak bands in the long wavelength wing of the spectrum near $560-630 \mathrm{~nm}(2.2-$ $1.95 \mathrm{eV})[5-8,26-28]$.

These bands have various nature. The short wavelength bands are caused by exciton transitions arisen from different regions of the crystal lattice (regular and lead-deficient regions for blue and green emissions, respectively) [26-28]. In addition, the tunneling recombination on $\mathrm{WO}_{3}$ defects was considered as the origin of the green emission $[28,29]$. Two bands in the yellow-red spectral range are usually connected with defects, e.g., lead vacancies [5,29]. Assuming the previous experience, different types of defects take part in the formation of LCs responsible for the PWO emission. In the present investigation, we will analyze changes in the PWO matrix emission caused by the impact of factors affecting the defect composition of the lattice. The doping of some impurities and the thermal treatment are of such factors.

The triply charged RE ions are the matrix modifying impurities considered in this work. Thus, the future discussion requires a previous consideration of the arrangement of $\mathrm{RE}^{3+}$ ions in the PWO crystal lattice and their possible effects on the composition of defects in the matrix. The high-density packing of the PWO crystal lattice $\left(\rho=8.28 \mathrm{~g} / \mathrm{cm}^{3}\right)$ excludes the possibility of the arrangement of RE impurities in interstitial positions $[30,31]$. The most probable case is the incorporation of $\mathrm{RE}^{3+}$ ions in the $\mathrm{Pb}^{2+}$ sites. The excess positive charge is compensated by lead vacancies (one lead vacancy for two replacements). The scheelite-type $\mathrm{PbWO}_{4}$ crystal structure is tetragonal, and the space group is $I 4_{1} / a, Z=4$. It includes the $\mathrm{Pb}$ atoms in eight oxygen surrounding. These oxygen atoms belong to $\mathrm{WO}_{4}$ groups of $D_{2 d}$ local symmetry. The distorted $\mathrm{PbO}_{8}$ polyhedra have $S_{4}$ site symmetry [30-32].
On the other hand, the most authors investigated the spectroscopy of $\mathrm{RE}^{3+}$ ions in the PWO crystals have observed the formation of two types of LCs on the basis of impurity $\mathrm{RE}^{3+}$ ions in these compounds [33-38]. Moreover, three or six types of $\mathrm{LCs}$ formed by $\mathrm{Eu}^{3+}$ ions were observed for the annealed $\mathrm{PWO}-\mathrm{Eu}^{3+}$ crystals. At the same time, only one type of LCs was found for the thermally untreated crystals [39]. There are two main points of view on the origin of several types of the RE centers in PWO crystals. The simplest and less spread one considers that various types of centers are formed by oxygen vacancies located at the different positions in the $\mathrm{PbO}_{8}$ octagon $[39,40]$. The $\mathrm{PbO}_{8}$ octagon has six nonequivalent oxygen positions with two pairs of equivalent oxygens [30,31]. However, the most investigators clearly observed only two types of centers. Moreover, in the case of five LCs, one of the centers arising at the highest impurity concentration has essentially different parameters compared to another four centers. Obviously, nonequivalent oxygen vacancies in the nearest surrounding of the impurity $\mathrm{RE}^{3+}$ ions could form various $\mathrm{LCs}$, but with strongly close spectral characteristics and differences between them are usually experimentally missed. One should remember the necessity of the charge compensation in the crystal lattice. Therefore, some authors consider that the second type of RE centers in the PWO crystals could arise whether the impurity RE ions occupy $\mathrm{W}$ positions $[10,11,41-$ 45]. Such replacement is accompanied by comparable large differences of charges and ionic radii. Different authors in different manners describe a possibility of such incorporation, but the physical approach is the same in all cases. On the one hand, some of crystal growers believe that the RE-doping of the PWO lattice leads to the formation of the $\mathrm{W}_{1-y} \mathrm{RE}_{y} \mathrm{O}_{3-x}$ phase, where $x<0.3[11,38,41,42]$. On the other hand, the creation of bonded impurity centers was considered. Those centers combine the $\mathrm{RE}$ ion in a $\mathrm{Pb}$ site, the $\mathrm{RE}$ ion in a $\mathrm{W}$ site, and oxygen vacancy: $\left[\mathrm{RE}_{\mathrm{V}(\mathrm{Pb})}^{3+}\right]^{1+}-\left[\mathrm{RE}_{\mathrm{V}(\mathrm{W})}^{3+}\right]^{3-}-[\mathrm{V}(\mathrm{O})]^{2+}\left[43^{-}\right.$ 45]. In both cases, the $\mathrm{RE}_{\mathrm{V}(\mathrm{W})}^{3+}$ replacement leads to the charge compensation of some oxygen vacancies, that changes the composition of the matrix emission LCs ensemble related to oxygen vacancies.

Really, it was shown previously that the RE-doping decreases the concentration of oxygen vacancies in tungstates [46-49]. The lead and oxygen vacancies are

ISSN 2071-0194. Ukr. J. Phys. 2019. Vol. 64, No. 9 
the most probable types of defects for the PWO crystals grown by the Czochralski method due to a comparably low evaporation temperature of $\mathrm{PbO}$ oxide used in the blend [50]. It should be noted that the expected concentration of $\mathrm{RE}$ ions in $\mathrm{W}$ positions is significantly lower than in $\mathrm{Pb}$ positions [38]. Therefore, the RE-doping decreases concentrations of various vacancies in the PWO crystal lattice, and this decrease especially concerns oxygen vacancies. The comparative analysis of spectral properties of the matrix emission of the undoped and RE-doped crystals carried out with consideration of this feature of the PWO lattice should give more information about the structure of LCs responsible for the matrix emission.

\section{Experiment}

The investigated samples were grown by the Czochralski method using a "Crystal-617" installation from lead and tungsten oxides. Into the activated samples, the impurities were added in a blend as corresponding rare earth oxides. Details of the procedure have been described previously in [27].

Luminescence measurements were carried out using the synchrotron radiation at SUPERLUMI station at HASYLAB (DESY), Hamburg, Germany. The excitation energy range is $3.7-25 \mathrm{eV}$ (for more details, see [51]). The recorded spectra were corrected for the spectral sensitivity of the registration equipment. All the spectra were measured on the wavelength scales. In order to carry out the correct decomposition of the spectra into contributing bands, we perform the conversion of the recorded spectra from the wavelength scale to the energy one. Conversions and decompositions of the emission spectra were carried out using the procedure described previously for the excitation spectra.

\section{Results}

Emission spectra of the undoped PWO crystal at low temperatures consist of bands in the $1.5-3.5 \mathrm{eV}$ photon energy range with maxima at about $2.65-2.7 \mathrm{eV}$ at $\hbar \omega_{\text {ex }} \geq 4.1 \mathrm{eV}$. The extended low-energy sides of the spectra obtained at the noted excitations contain also at least one spectral component with low intensity located near $2.15 \mathrm{eV}$. The spectra excited with $\hbar \omega_{\text {ex }} \leq 4.0 \mathrm{eV}$ consist of bands in the 1.5$3.0 \mathrm{eV}$ photon energy range. These spectra have maxima at about 2.4 and $2.15 \mathrm{eV}$ and a weak component with maximum near $2.0 \mathrm{eV}$ (Fig. 1). Intensities of the

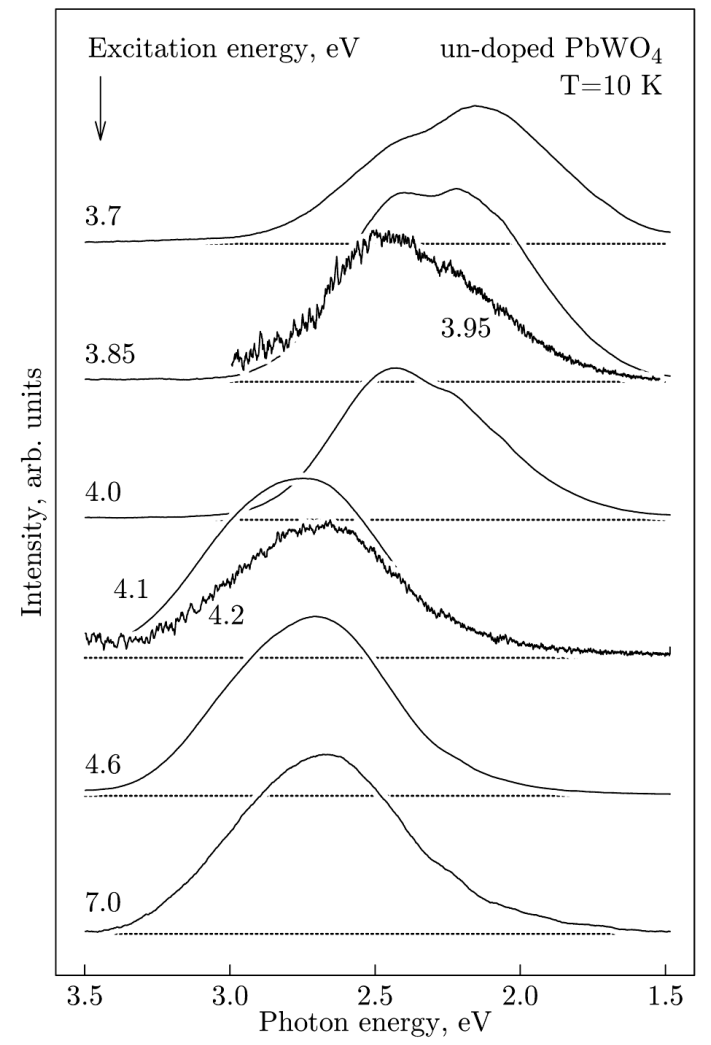

Fig. 1. Emission spectra of the undoped $\mathrm{PbWO}_{4}$ samples at excitations with $7.0,4.6,4.2,4.1,4.0,3.95,3.85$, and $3.7 \mathrm{eV}$; $T=10 \mathrm{~K}$

bands located at $2.65-2.7 \mathrm{eV}$ are higher by 10 times compared to the intensities of low-energy bands.

Increasing the temperature to $300 \mathrm{~K}$ leads to an essential decrease of the emission intensity in the 1.5$2.5 \mathrm{eV}$ photon energy range and to the appearance of an IR band in the $1.2-1.5 \mathrm{eV}$ range (Fig. 2). The shapes of the spectra in the $1.5-2.5 \mathrm{eV}$ range at $300 \mathrm{~K}$ are different from the corresponding spectra observed at $10 \mathrm{~K}$ : we clearly see the presence of a band with maximum at $3.1 \mathrm{eV}$. This band cannot be separated in the spectra at low temperatures compared to the band with maximum at $2.65-2.7 \mathrm{eV}$ which dominates in the spectra at $10 \mathrm{~K}$.

Therefore, the luminescence spectra of PWO crystals have complex character with the intricate overlapping of emission bands possessing different dependences on the temperature and excitation wavelengths. That is why, the correct decomposition of the spectra into separated components is one of the main steps on the way to the development of physical 


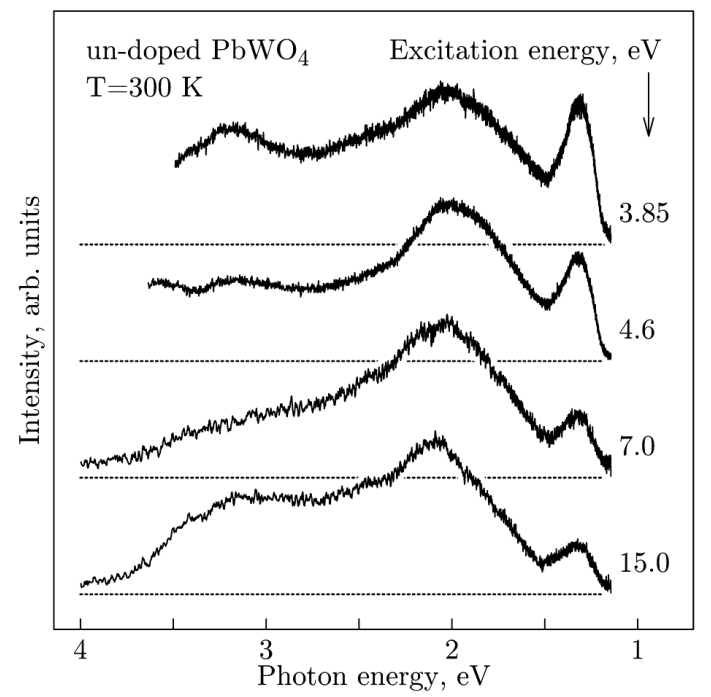

Fig. 2. Emission spectra of the undoped $\mathrm{PbWO}_{4}$ samples at excitations with $15.0,7.0,4.6$, and $3.85 \mathrm{eV} ; T=300 \mathrm{~K}$

models describing the processes responsible for the appearance of the observed luminescence. For a successful decomposition of the obtained experimental spectra into individual bands, we need as full as possible data for the determination of input spectral components. Such data could be obtained by the comparable investigation of the matrix emission of pure and doped PWO crystals, because it is expected that the impurities affect different LCs of matrix emission in different ways.

Shapes of the RE-doped spectra have differences with undoped ones. Maxima of the main PL band were found to be shifted to the higher photon energies. For the $\mathrm{Eu}^{3+}$-doped $\mathrm{PbWO}_{4}$ crystals, these maxima are near 2.7 and $2.75 \mathrm{~nm}$ at 4.1 and $4.6 \mathrm{eV}$ excitations, respectively (Fig. 3). For the crystals with $\mathrm{Yb}^{3+}$ and $\mathrm{Pr}^{3+}$ impurities, the maxima are $2.8 \mathrm{eV}$ at $\hbar \omega_{\mathrm{ex}} \leq 4.1 \mathrm{eV}$ (Figs. 4 and 5; [52]). Thus, the adding of the $\mathrm{Pr}^{3+}$ and $\mathrm{Yb}^{3+}$ impurities shifts the maximum of the main band from $2.65-2.7 \mathrm{eV}$ for the undoped crystals to $2.8 \mathrm{eV}$ for the doped ones (Figs. 1, $4,5)$. Such shifts of the maximum position can be a result of the variations of contributions of different bands, strong overlapping of which does not allow one to clearly see their maximum positions at low temperatures. Really, the spectra obtained at room temperature show the contribution of a component with the maximum at about $3.1 \mathrm{eV}$ (Fig. 2). Therefore, we suppose that the main band contain components with

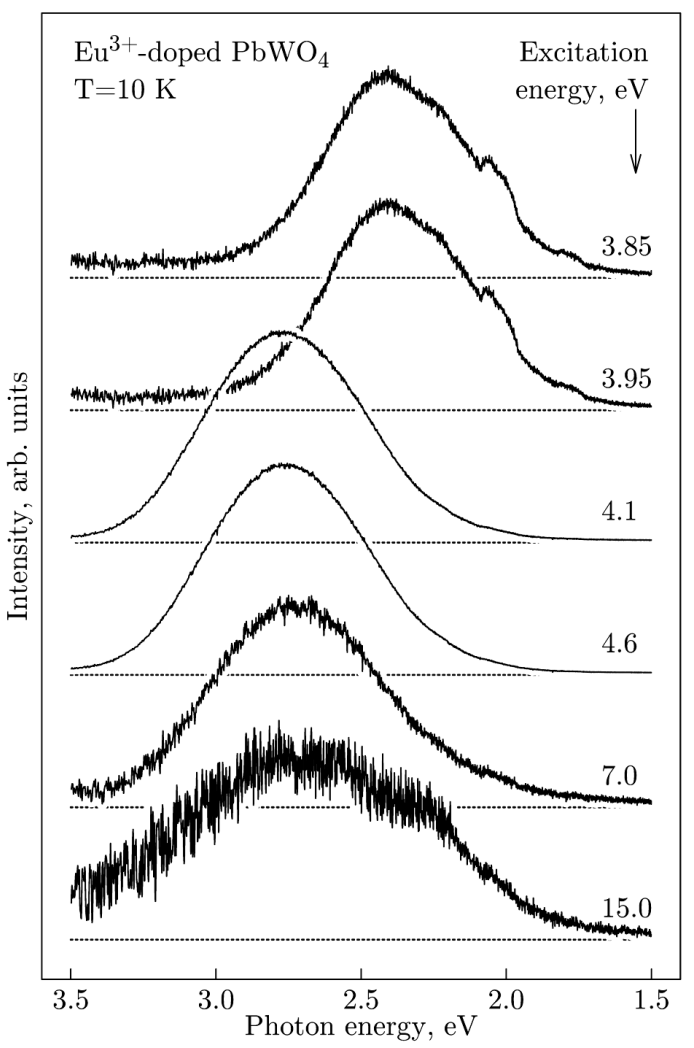

Fig. 3. Emission spectra of the $\mathrm{Eu}^{3+}$-doped $\mathrm{PbWO}_{4}$ samples at excitations with $15.0,7.0,4.6,4.1,3.85$, and $3.95 \mathrm{eV} ; \mathrm{T}=$ $=10 \mathrm{~K}$

maxima near 3.1 and $2.65 \mathrm{eV}$. The long-wavelength part of the spectrum is also complex. Comparing the spectra recorded at $3.7,3.85-3.95$, and $4.0 \mathrm{eV}$ excitations, one could found the presence of bands with maxima at about $2.0,2.2$, and $2.4 \mathrm{eV}$, respectively (Figs. 1, 4, and 5). Assuming this observations, we suppose that the spectra of low-temperature matrix emission could contain five wide band components located near 2.0, 2.2, 2.4, 2.65, and $3.1 \mathrm{eV}$.

Analyzing the spectra of RE-doped samples, we should consider the possibility of contributions of the impurity ions to the resulting spectra. The applied impurities are characterized by a linear emission originated from the $f$ - $f$ transitions in the corresponded ions. In the case of $\mathrm{Eu}^{3+}$ impurities, the linear spectra are weak at the applied excitations and can be found in the 2.0-2.2 and 1.7-1.8 eV intervals (Fig. 4). The spectroscopy of $\mathrm{Eu}^{3+}$ impurities in the PWO crystals was investigated formerly in $[34,38]$. The $\mathrm{Yb}^{3+}$ ions are characterized by a linear emission in the IR

ISSN 2071-0194. Ukr. J. Phys. 2019. Vol. 64, No. 9 


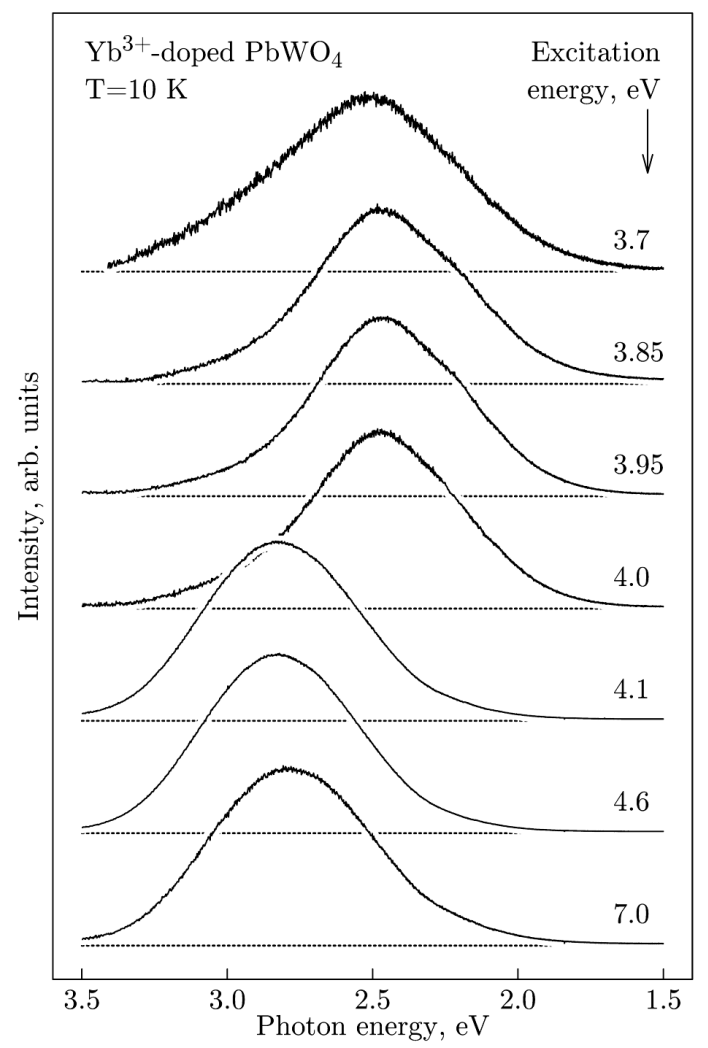

Fig. 4. Emission spectra of $\mathrm{Yb}^{3+}$-doped $\mathrm{PbWO}_{4}$ samples at excitations with $7.0,4.6,4.1,4.0,3.95,3.85$, and $3.7 \mathrm{eV}$; $T=10 \mathrm{~K}$

region, which does not overlap with the matrix emission range [52]. The $\mathrm{Yb}^{3+}$ ions are also characterized by wide band charge transfer luminescence spectra with maxima at about 2.5 and $3.7 \mathrm{eV}$, which can be excited by radiation from the $5.0-6.2 \mathrm{eV}$ energy interval $[53,54]$. We have not applied excitations from the noted region to the $\mathrm{Yb}^{3+}$-doped $\mathrm{PbWO}_{4}$ samples. Therefore, these bands are not observed in the spectra of $\mathrm{Yb}^{3+}$-doped $\mathrm{PWO}$ crystals that were already briefly reported recently $[52,55]$. The linear structure of $\mathrm{Pr}^{3+}$-doped samples is rich for details.

More than 20 lines of inner $f$ - $f$ transitions were observed in the 1.6-2.6 eV interval. In addition, the spectra of $\mathrm{Pr}^{3+}$-doped crystals contain narrow failures in the 2.6-2.8 interval (Fig. 5). These failures are caused by re-absorption of the matrix emission by $\operatorname{Pr}^{3+}$ impurity ions [10].

Before the decompositions, the measured spectra were normalized on their maxima. For the procedure of decomposition of the spectra, we have used the

ISSN 2071-0194. Ukr. J. Phys. 2019. Vol. 64, No. 9

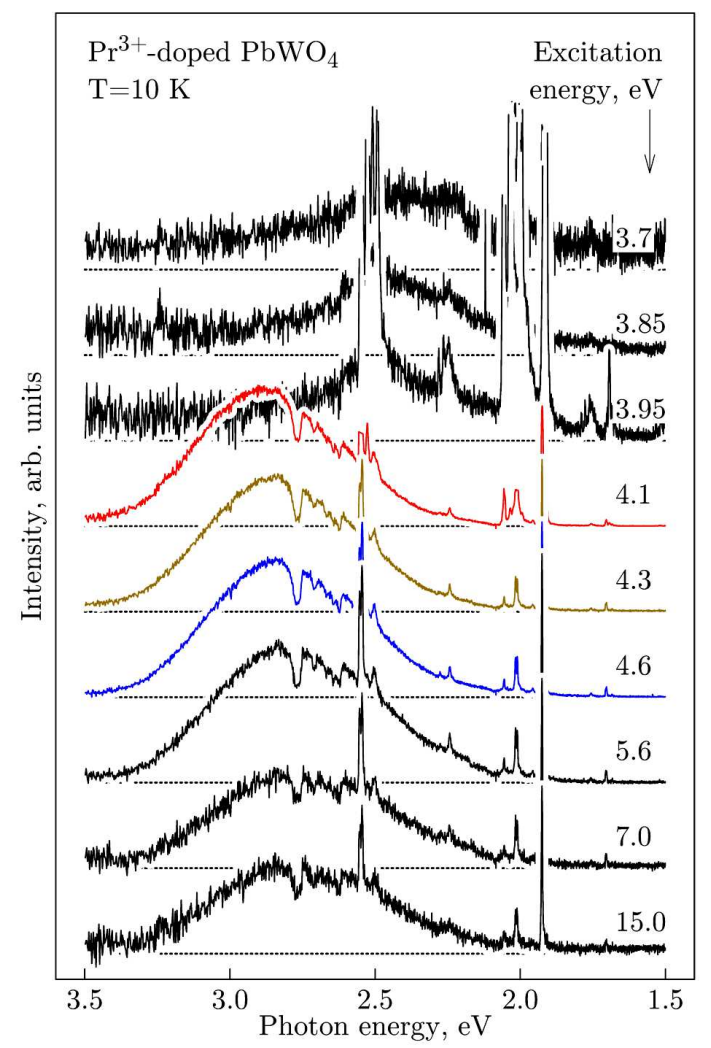

Fig. 5. Emission spectra of $\mathrm{Pr}^{3+}$-doped $\mathrm{PbWO}_{4}$ samples at excitations with $15.0,7.0,5.6,4.6,4.3,4.1,3.95,3.85$, and $3.7 \mathrm{eV} ; T=10 \mathrm{~K}$

bands obtained from the above-described analytical analysis at $2.0,2.2,2.4,2.65$, and $3.1 \mathrm{eV}$ as starting maximum positions. After the fitting, we have obtained the positions of maxima of the decomposition components that are somewhat different from the starting ones. There are bands at 1.95, 2.2, 2.45, 2.7 , and $3.0 \mathrm{eV}$. All the measured spectra were combined with these bands. The results of corrections and decomposition of the spectra are presented in Fig. 6 for the undoped and Eu-doped samples. The obtained data on the contributions of the above-noted separated bands in the emission spectra measured at various excitations are collected in Tables $1-4$. They present the relative intensities for each of the bands obtained under the decomposition of the normalized corrected spectra.

\section{Discussion}

The main result of the performed decomposition is the assumption that the luminescence emission 


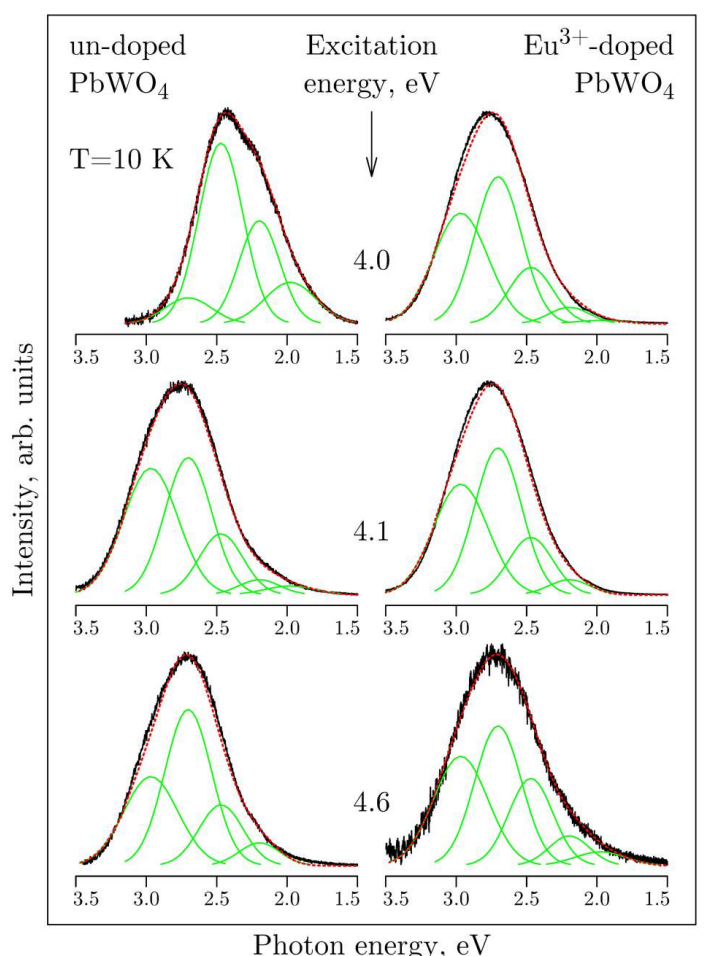

Fig. 6. Decomposition of the emission spectra of the undoped (left) and $\mathrm{Eu}^{3+}$-doped (right) $\mathrm{PbWO}_{4}$ samples into individual bands; $T=10 \mathrm{~K}$; at excitations with 4.0, 4.1, and $4.6 \mathrm{eV}$ (from top to borrom). Dashed curves show the sums of individual bands

Table 1. Results of the decomposition of emission spectra of the undoped $\mathrm{PbWO}_{4}$ crystals; $T=10 \mathrm{~K}$

\begin{tabular}{|c|c|l|l|l|l|l|}
\hline \multirow{2}{*}{ No. } & \multirow{2}{*}{$\begin{array}{c}\text { Excitation } \\
\text { energy, eV }\end{array}$} & \multicolumn{4}{|c|}{ Components of decomposition, eV } \\
\cline { 3 - 7 } & & 1.95 & 2.2 & 2.45 & 2.7 & 3.0 \\
\hline & & & & & \\
1 & 3.70 & 0.65 & 0.5 & 0.5 & 0.1 & - \\
2 & 3.85 & 0.4 & 0.6 & 0.8 & 0.1 & - \\
3 & 3.95 & 0.24 & 0.5 & 0.85 & 0.15 & - \\
4 & 4.00 & 0.2 & 0.5 & 0.9 & 0.1 & - \\
5 & 4.10 & 0.05 & 0.1 & 0.3 & 0.65 & 0.6 \\
6 & 4.20 & 0.05 & 0.1 & 0.35 & 0.75 & 0.35 \\
7 & 4.60 & - & 0.1 & 0.3 & 0.75 & 0.4 \\
8 & 7.00 & 0.1 & 0.1 & 0.4 & 0.7 & 0.5 \\
\hline
\end{tabular}

of undoped and RE-doped samples consists of the same five bands (Tables 1-4). The spectral components obtained by the decomposition can be correlated with the main emission bands discussed previously for the PWO crystals. The bands located at 3.0,
Table 2. Results of the decomposition of emission spectra of the $\mathrm{Eu}^{3+}$-doped $\mathrm{PbWO}_{4}$ crystals; $\mathrm{T}=10 \mathrm{~K}$

\begin{tabular}{|c|c|c|l|l|l|l|}
\hline \multirow{2}{*}{ No. } & \multirow{2}{*}{$\begin{array}{c}\text { Excitation } \\
\text { energy, eV }\end{array}$} & \multicolumn{5}{|c|}{ Components of decomposition, eV } \\
\cline { 3 - 7 } & & 1.95 & 2.2 & 2.45 & 2.7 & 3.0 \\
\hline \multirow{2}{*}{1} & 3.85 & 0.1 & 0.55 & 0.8 & 0.15 & - \\
2 & 3.95 & 0.1 & 0.55 & 0.8 & 0.15 & - \\
3 & 4.1 & - & 0.1 & 0.25 & 0.65 & 0.5 \\
4 & 4.6 & - & 0.1 & 0.25 & 0.7 & 0.5 \\
5 & 7.0 & 0.05 & 0.15 & 0.4 & 0.7 & 0.5 \\
\hline
\end{tabular}

Table 3. Results of the decomposition of emission spectra of the $\mathrm{Yb}^{3+}{ }_{- \text {doped }} \mathrm{PbWO}_{4}$ crystals; $T=10 \mathrm{~K}$

\begin{tabular}{|c|c|l|l|l|l|l|}
\hline \multirow{2}{*}{ No. } & \multirow{2}{*}{$\begin{array}{c}\text { Excitation } \\
\text { energy, eV }\end{array}$} & \multicolumn{4}{|c|}{ Components of decomposition, eV } \\
\cline { 3 - 7 } & & 1.95 & 2.2 & 2.45 & 2.7 & 3.0 \\
\hline & 3.7 & 0.15 & 0.35 & 0.7 & 0.5 & 0.3 \\
2 & 3.85 & 0.1 & 0.4 & 0.8 & 0.3 & 0.1 \\
3 & 3.95 & 0.1 & 0.4 & 0.8 & 0.3 & 0.1 \\
4 & 4.0 & 0.05 & 0.4 & 0.8 & 0.35 & 0.15 \\
5 & 4.1 & - & 0.05 & 0.2 & 0.7 & 0.8 \\
6 & 4.6 & - & 0.05 & 0.15 & 0.6 & 0.8 \\
7 & 7.0 & - & 0.05 & 0.2 & 0.8 & 0.7 \\
\hline
\end{tabular}

Table 4. Results of the decomposition of emission spectra of the $\mathrm{Pr}^{3+}$-doped $\mathrm{PbWO}_{4}$ crystals; $T=10 \mathrm{~K}$

\begin{tabular}{|c|c|c|c|c|c|c|}
\hline \multirow{2}{*}{ No. } & \multirow{2}{*}{$\begin{array}{c}\text { Excitation } \\
\text { energy, eV }\end{array}$} & \multicolumn{5}{|c|}{ Components of the decomposition, eV } \\
\cline { 3 - 7 } & & 1.95 & 2.2 & 2.45 & 2.7 & 3.0 \\
\hline \multirow{2}{*}{1} & 3.85 & 0.2 & 0.25 & 0.75 & 0.3 & - \\
2 & 4.1 & - & 0.05 & 0.2 & 0.6 & 0.7 \\
3 & 4.3 & - & 0.05 & 0.2 & 0.6 & 0.7 \\
4 & 4.6 & - & 0.05 & 0.2 & 0.6 & 0.7 \\
5 & 5.6 & 0.05 & 0.1 & 0.3 & 0.6 & 0.6 \\
6 & 7.0 & 0.05 & 0.1 & 0.4 & 0.6 & 0.7 \\
\hline
\end{tabular}

2.7, and $2.45 \mathrm{eV}$ correspond to the blue, blue-green (green GII in [26]), and green (GI in [26]) bands, respectively. Then the bands with maxima at 2.2 and $1.95 \mathrm{eV}$ have to be marked as yellow and red bands, respectively [25-29].

Some effects of the RE impurities on the studied matrix emission are clearly seen in Fig. 5. In particular, the relative intensities of the $3.0 \mathrm{eV}$ band for the RE-doped samples are by $30-50 \%$ higher ISSN 2071-0194. Ukr. J. Phys. 2019. Vol. 64, No. 9 
than for undoped samples (Table 1). The behavior of the $2.7 \mathrm{eV}$ band depends on the excitation wavelength (Table 1). The relative intensities of the 2.45 and $2.2 \mathrm{eV}$ bands insignificantly fall down with the RE doping (Tables 3 and 4). The intensity of the $1.95 \mathrm{eV}$ band in the spectra of the RE-doped samples is strongly decreased by 2 or 3 times (Fig. $5, e$ ). Thus, we can consider the structure of centers responsible for the different types of emission with regard for the possible effects of $\mathrm{RE}$ ions on the defect composition in the PWO lattice.

\subsection{Blue band with maximum at $3.0 \mathrm{eV}$}

The results obtained in the present work show that the adding of $\mathrm{RE}$ ions leads to an essential increase (up to 2 times) in the relative contribution of this band. It is known that the blue luminescence of PWO crystals is caused by the emission of excitons [5-8], but the features of these excitons are still under discussion [26-29]. It was supposed that the blue emission arises from the $\mathrm{WO}_{4}^{2-}$-related exciton states of the regular PWO structure [8, 26]. Various authors reported different effects of the annealing on the blue emission characteristics for the undoped and REdoped PWO crystals $[40,51,56]$ and the influence of impurity RE ions on the profiles of their excitation spectra [5,27]. We have supposed previously that impurity RE ions mainly affect the properties of the blue luminescence at a stage of excitation viz., creation of excitons [27]. The idea is now accepted that excitons in the PWO crystals are created on the $\mathrm{Pb}^{2+}$ cations disturbed with a neighbor defect $[6-8,27,57]$. We assumed that the RE impurities could create defects responsible for the formation of an additional channel of exciton creation. The defects, which can play roles of disturbing neighbors, can be in the anion sublattice (oxygen vacancies) and in the cation one (lead vacancies or impurities in the $\mathrm{Pb}$ positions). In the case of undoped PWO crystals, the most probable defects affecting the $\mathrm{Pb}^{2+}$ cations taking part in the creation of excitons are oxygen vacancies $\left(\mathrm{V}_{\mathrm{O}}\right)$.

The main types of defects in the RE-doped PWO doped crystals are the RE ions incorporated in the $\mathrm{Pb}$ positions $\left(\mathrm{RE}_{\mathrm{Pb}}\right)$. Such defects can be suitable electron traps. Therefore, excitons are mainly created on $\mathrm{Pb}^{2+}$ cations that are parts of the LCs including the $\mathrm{Pb}^{2+}$ cation and a defect $\left(\mathrm{V}_{\mathrm{O}}\right.$ and $\mathrm{RE} \mathrm{Pb}$ for undoped and doped crystals, respectively). Then the excitons created with participation of various defects might be localized and disintegrate at the same centers in the crystal lattice independently of the type of LCs, where they were created. Such excitons will give the same emission band. This assumption agrees with previous suppositions that the blue band arises from the $\mathrm{WO}_{4}^{2-}$-related excitons in the regular PWO crystal lattice [26-29].

The proposed model allows us to explain the observed previously differences between effects of the annealing on the blue emission of undoped and REdoped crystals: the shapes of emission spectra of the undoped PWO crystals are sensitive to thermal treatments at high temperatures contrary to the stability of properties of the RE-doped crystals $[40,51,58]$. In the proposed model, excitons in the case of undoped samples are created on the $\mathrm{Pb}^{2+}$ cations disturbed by $\mathrm{V}_{\mathrm{O}}$ defects. The thermal treatment of crystals in the oxygen-rich atmosphere leads to the filling of the VO defects. Thus, the annealing decreases the content of the corresponding centers in the crystal lattice and affects the relative intensity of the blue emission. In the case of RE-doped crystals, excitons are created on the $\mathrm{Pb}^{2+}-\mathrm{RE}_{\mathrm{Pb}}$ centers. Such centers are stable under the action of a thermal treatment. Therefore, the related emission does not depend on the annealing.

\subsection{Blue-green band}

\section{with maximum at $2.7 \mathrm{eV}$}

The relative contribution of this band to the total spectrum insignificantly falls down in the REdoped samples (Tables 2-4). According to [26-28], this band arises from the $\mathrm{WO}_{4}^{2-}$-type excitons from the lead-deficient regions in the crystal structure. The doping with RE ions decreases the content of the lead-deficient regions in the PWO crystal lattice, because the impurity cations fill the $\mathrm{Pb}$ vacancies $[38$ 42]. Thus, the observed insignificant decrease of the $2.7 \mathrm{eV}$ band in the RE-doped samples is in agreement with the made previously conclusions concerning the relation of the blue-green emission from $\mathrm{WO}_{4}^{2-}$-type excitons with the lead-deficient scheelite-type structure [26-28]. As we have observed previously, the blue-green band intensity is not sensitive to the thermal treatment neither for the undoped PWO crystals, nor for the RE-doped ones [51]. This observation also supports the proposed model, as the annealing does not fill the $\mathrm{Pb}$ vacancies. 


\subsection{Green band with maximum at $2.45 \mathrm{eV}$}

The intensity of this band depends on the RE doping insignificantly. We have observed dissimilar effects for the various RE ions (Fig. 5, c). Obviously, the spectra of this band are strongly overlapped with electron transitions in the impurity ions that withdraw the excitation energy to RE emission centers. This is clearly observed for $\mathrm{Pr}^{3+}$-doped PWO crystals and more weakly for $\mathrm{Eu}^{3+}$-doped ones in the 4.10-4.6 eV excitation interval. Really, the excitation spectra of luminescence of the corresponding impurity ions have the bands in this spectral interval [34, 35, 38-40]. In addition, some decrease of the green band intensity was observed in the case of $\mathrm{Yb}^{3+}$ impurities which have no strong excitation bands in the noted interval $[53,54]$. The relative contribution of the green band does not depend on the presence of impurities at the excitation from the $3.7-4.0 \mathrm{eV}$ interval. The noted excitations give the most intense contribution of the green band for the undoped crystals. The 3.7$4.0 \mathrm{eV}$ excitation band is located below the absorption edge of the PWO crystals in the region of absorption of defects (Fig. 7) [51,57]. In works [26-28], it was supposed that the green band is caused by the tunneling recombination between electron and hole centers. Various defects were considered as possible candidates on components of the corresponding LCs. It was considered that $\mathrm{Pb}$ vacancies $[28]$ or $\mathrm{WO}_{3}$ defects [26] could be hole components. According to the results obtained in this paper, the formation of the LCs responsible for the $2.45 \mathrm{eV}$ band does not depend on the presence of RE impurities in the lattice, but these centers lose considerably the excitation energy by its transfer to the impurity RE centers at excitation ener-

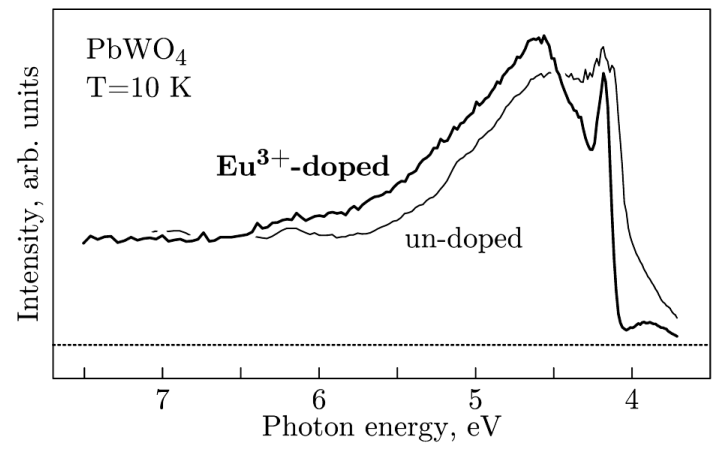

Fig. 7. Excitation spectra measured at $2.7 \mathrm{eV}$ emission of the undoped and $\mathrm{Eu}^{3+}$-doped $\mathrm{PbWO}_{4}$ samples; $T=10 \mathrm{~K}$ gies higher than $4.1 \mathrm{eV}$. Therefore, it is unlikely that the cation vacancies take part in the processes giving the $2.45 \mathrm{eV}$ emission band. So, the green band has to be connected with the $\mathrm{WO}_{3}$ hole centers. Such result agrees with obtained previously data on the thermal stability of $\mathrm{WO}_{3}$ centers [26] and no observation of the annealing effect on the green band in the undoped and RE-doped PWO crystals [51].

\subsection{Yellow band} with maximum at $2.2 \mathrm{eV}$

The relative intensity of this band depends on the RE doping insignificantly (Tables 1-4). On the other hand, the annealing decreases the intensity of this band [51]. Such behavior of the yellow band supports the formerly made assumption that this emission is related to interstitial oxygen anions [25].

\subsection{Red band} with maximum at $1.95 \mathrm{eV}$

The addition of RE ions strongly decreases the relative intensity of this band. It was already shown previously that the red emission arises due to the lead vacancies [29] or to the presence of $\mathrm{Pb}^{3+}-\mathrm{V}_{\mathrm{Pb}}-\mathrm{F}$-complex centers [58].

The participation of lead vacancies in the formation of red emission centers agrees with the significant decrease of the $1.95 \mathrm{eV}$ band in the RE-doped crystals observed in this paper, because the RE ions decrease the content of lead vacancies in the PWO crystal lattice. But, we think that the red emission complex centers could have a simpler structure of the $\mathrm{Pb}^{2+}-\mathrm{V}_{\mathrm{Pb}}$ type. The IR band with maximum at $1.3 \mathrm{eV}$ was observed only for undoped crystals. This band is thermally activated, and its intensity at room temperature at some excitations under the noted conditions can be comparable with the blue band intensity (Fig. 2). It is well excited in the excitation bands of the red emission. We suppose that the IR band arises on the centers of the red emission from the states thermally activated by lattice vibrations. It was shown previously that the potential curve with two extrema is characteristic of the PWO crystals [25]. The disappearance of this band in the RE-doped crystals agrees with a considerable decrease of the red band intensity for the RE-doped crystals.

\section{Conclusions}

We have investigated the structure of the PWO emission spectra. The RE impurities are used in order to

ISSN 2071-0194. Ukr. J. Phys. 2019. Vol. 64, No. 9 
obtain more information about the composition of the spectra and the structure of luminescence centers. The decomposition of the spectra into individual bands reveals that all the matrix emission spectra of the undoped and RE-doped PWO crystals measured at $10 \mathrm{~K}$ consist of the same five strongly overlapping bands at $3.0,2.7,2.45,2.2$, and $1.95 \mathrm{eV}$. The 3.0 and $2.7 \mathrm{eV}$ bands have the excitonic nature. The 2.2 and $1.95 \mathrm{eV}$ bands are supposed to be connected with interstitial oxygen and lead vacancies, respectively.

Effects of the $\mathrm{RE}^{3+}$ doping and the annealing on the relative intensities of separated bands are studied. It is shown that the $\mathrm{RE}^{3+}$ doping increases the intensity of the $3.0 \mathrm{eV}$ band by the formation of an additional RE-induced channel of creation of excitons.

The annealing of the undoped crystals in the oxygen-containing atmosphere leads to a decrease of the relative intensity of the $3.0 \mathrm{eV}$ band, but only for the undoped crystals, when the creation of excitons occurs on the centers, including oxygen vacancies. The $2.45 \mathrm{eV}$ green band was connected with the $\mathrm{WO}_{3}$ centers. The formation of those centers does not depend on the RE doping. They are also stable under conditions of a thermal treatment. But, the $\mathrm{RE}^{3+}$ impurity centers can decrease the excitation efficiency of the $2.45 \mathrm{eV}$ green emission, especially it concerns the excitations from the $3.7-$ $4.0 \mathrm{eV}$ energy interval. The considerable suppression of the $1.95 \mathrm{eV}$ band was observed for the $\mathrm{RE}^{3+}$ doped crystals. It is explained by a decrease of the concentration of $\mathrm{Pb}$ vacancies in the $\mathrm{RE}^{3+}$-doped crystals.

All the observed actions of the annealing and $\mathrm{RE}^{3+}$ doping on the centers of matrix emission of the PWO crystals have the same character for different RE ions and agree with data observed previously by many other authors. Thus, the data on properties of the five matrix emission bands studied in this work can be used for the prediction of spectral characteristics of newly synthesized luminescent materials based on $\mathrm{PbWO}_{4}$ compositions.

This publication is based on the research received the funding from the Ministry of Education and Science of Ukraine. Measurements with synchrotron radiation were done at the SUPERLUMI station at HASYLAB (DESY), Hamburg, Germany.
1. R. Djilkibaev, L. Heinrich, A.I. Mincer, C. Musso, P. Nemethy, J. Sculli, A. Toropin, L. Zhao. Lead-tungstate scintillator studies for a fast low-energy calorimeter. J. Instrumentation 5, P01003 (2010).

2. P. Lecoq. Ten years of lead tungstate development. Nucl. Instrum. Methods Phys. Res. A 537, 15 (2005).

3. V.V. Laguta, M. Nikl, S. Zazubovich. Physics of lead tungstate scintillators. IEEE Trans. Nucl. Sci. 55, 1275 (2008).

4. E. Auffray, M.V. Korzhik, S. Zazubovich. Luminescence and photothermally stimulated defects creation processes in $\mathrm{PbWO}_{4}: \mathrm{La}^{3+}, \mathrm{Y}^{3+}$ (PWO II) crystals. J. Lumin. 168, 256 (2015).

5. K.W. Meert, J.J. Joos, D. Poelman, P.F. Smet. Investigation of the quenching mechanisms of $\mathrm{Tb}^{3+}$ doped scheelites. J. Lumin. 173, 263 (2016).

6. D. Millers, L. Grigorjeva, S. Chernov, A. Popov, P. Lecoq, E. Auffray. The temperature dependence of scintillation parameters in $\mathrm{PbWO}_{4}$ crystals. Phys. Stat. Sol. (b) 203, 585 (1997).

7. M. Fujita, M. Itoh, M. Horimoto, H. Yokota. Fine structure of the exciton band and anisotropic optical constants in scheelite $\mathrm{PbWO}_{4}$ crystals. Phys. Rev. B 65, 195105 (2002).

8. M. Itoh, T. Sakurai. Time-resolved luminescence from Jahn-Teller split states of self-trapped excitons in $\mathrm{PbWO}_{4}$. Phys. Rev. B 73, 235106 (2006).

9. M. Anicete-Santos, E. Orhan, M.A. De Maurera, L.G.P. Simões, A.G. Souza, P.S. Pizani, E.R. Leite, J.A. Varela, J. Andres, A. Beltran, E. Longo. Contribution of structural order-disorder to the green photoluminescence of $\mathrm{PbWO}_{4}$. Phys. Rev. B 75, 165105 (2007).

10. O. Antonenko, O. Chukova, Yu. Hizhnyi, S. Nedilko, V. Scherbatskyi. Luminescent characterization of lead tungstate crystals doped with europium, praseodymium, and ytterbium ions. Optical Materials 28, 643 (2006).

11. S. Burachas, A. Apanasenko, B. Grinyov, V. Ryzhikov, K. Katrunov, M. Starzhinskiy, M. Ippolitov, V. Manko, G. Tamulaitis. Improvement of optical and luminescent characteristics and radiation hardness of $\mathrm{PbWO}_{4}$ crystals by doping with $\mathrm{Y}, \mathrm{Sb}$, and Mo impurities. Int. J. Inorganic Materials 3, 1101 (2001).

12. P. Lecoq. Organization of the production of 100 tons of lead tungstate crystals for the CMS experiment at CERN. Optical Materials 26, 523 (2004).

13. A.N. Caruso. The physics of solid-state neutron detector materials and geometries. J. Phys.: Condensed Matter 22, 443201 (2010).

14. D. Klimm, P. Reiche. Lead Tungstate (PWO) and other Scintillator Crystals. In: Encyclopedia of Materials: Science and Technology. Edited by K.H.J. Buschow et al. (Elsevier, 2001).

15. M.B. Kosmyna, B.P. Nazarenko, V.M. Puzikov, A.N. Shekhovtsov. Development of growth technologies for the photonic single crystals by the Czochralski method at Institute for Single Crystals, NAS of Ukraine. Acta Phys. Polon. 124, 305 (2013). 
16. X. Wang, B. Liu, Y. Yang. Luminescence properties of $\mathrm{PbWO}_{4}: \mathrm{Eu}^{3+}$ nanocrystals synthesized by a hydrothermal method. Optics and Laser Technology 58, 84 (2014).

17. R. Reisfeld. New developments in luminescence for solar energy utilization. Optical Materials 32, 850 (2011).

18. A. Hallaoui, A. Taoufyq, M. Arab, B. Bakiz, A. Benlhachemi, L. Bazzi, S. Villain, J-C. Valmalette, F. Guinneton, J-R. Gavarri. Influence of chemical substitution on the photoluminescence of $\mathrm{Sr}_{1-\mathrm{x}} \mathrm{Pb}_{\mathrm{x}} \mathrm{WO}_{4}$ solid solution. J. Solid State Chem. 227, 186 (2015).

19. K.V. Dabre, S.J. Dhoble, J. Lochab. Synthesis and luminescence properties of $\mathrm{Ce}^{3+}$ doped $\mathrm{MWO}_{4}(\mathrm{M}=\mathrm{Ca}, \mathrm{Sr}$ and Ba) microcrystalline phosphors. J. Lumin. 149, 348 (2014).

20. Y. Zorenko, V. Gorbenko, A. Voloshinovskii, G. Stryganyuk, S. Nedilko, V. Degoda, O. Chukova. Luminescence of Sc-related centers in single crystalline films of $\mathrm{Lu}_{3} \mathrm{Al}_{5} \mathrm{O}_{12}$ garnet. Phys. Stat. Sol. (c) 2, 105 (2005).

21. V.B. Mikhailik, H. Kraus, M. Itoh, D. Iri, M. Uchida. Radiative decay of self-trapped excitons in $\mathrm{CaMoO}_{4}$ and $\mathrm{MgMoO}_{4}$ crystals. J. Phys.: Condensed Matter 17, 7209 (2005).

22. F. Kang, Y. Hu, H. Wu, Z. Mu, G. Ju, C. Fu, N. Li. Luminescence and red long afterglow investigation of $\mathrm{Eu}^{3+}$ $\mathrm{Sm}^{3+}$ co-doped $\mathrm{CaWO}_{4}$ phosphor. J. Lumin. 132, 887 (2012).

23. N.V. Klassen, S.Z. Shmurak, B.S. Redkin, S.I. Rybchenko, V.V. Sinitzin. Processing technology and scintillation performance of PWO. In: Proc. Int. Workshop on Lead Tungstate Crystals. Roma, Italy, October 12-14, 1998. Edited by S. Baccaro et al., La Sapienza Press, pp. 35-47.

24. P. Bohachek, N. Solovieva, M. Nikl. Formation of absorption and emission centres in $\mathrm{PbWO}_{4}$ surface layers induced by mechanical processing. Phys. Stat. Sol. (c) 2, 81 (2005).

25. S.G. Nedilko, A.S. Voloshinovskii, M.O. Krisjuk, Z.T. Moroz, M.V. Pashkovskyi. Impure and defect lead tungstate single crystals: X-ray and photoluminescence properties. In: Proceedings of SCINT'95 Conference. Edited by P. Dorenbos, C.W.E. van Eijk (Delft University Press, 1996), pp. 263-267 [ISBN: 9789040712159].

26. V. Babin, P. Bohachek, A. Krasnikov, M. Nikl, A. Stolovits, S. Zazubovich. Origin of green luminescence in $\mathrm{PbWO}_{4}$ crystals. J. Lumin. 124, 113 (2007).

27. O. Chukova, S. Nedilko. Study of RE-impurity effects on exciton luminescence of $\mathrm{PbWO}_{4}$ single crystals grown by Czochralski method. Optical Materials 35, 1735 (2013).

28. P. Fabeni, V. Kiisk, A. Krasnikov, M. Nikl, G.P. Pazzi, I. Silidos, S. Zazubovich. Tunneling recombination processes in $\mathrm{PbWO}_{4}$ crystals. Phys. Stat. Sol. (c) 4, 918 (2007).

29. P. Bohacek, N. Senguttuvan, V. Kiisk, A. Krasnikov, M. Nikl, I. Sildos, Y. Usuki, S. Zazubovich. Red emission of $\mathrm{PbWO}_{4}$ crystals. Radiation Measurements 38, 623 (2004).

30. Y. Huang, W. Zhu. The effects of sequential annealing in air atmosphere on luminescence properties of $\mathrm{PbWO}_{4}$ sin- gle crystal. J. Electron Spectros. Rel. Phenomena 133, 39 (2003).

31. T. Fujita, I. Kawada, K. Kato. $\mathrm{BaWO}_{4}$ - II (a high-pressure form). Acta Crystallogr. B 30, 2069 (1974).

32. B.G. Wybourne. Spectroscopic Properties of Ions in Crystals (Wiley, 1965).

33. O. Chukova, S. Nedilko, V. Scherbatskyi. Effects of $\mathrm{RE}$ doping on formation of emission centers in $\mathrm{PbWO}_{4}$ crystals. In: Proc. of Intern. Conf. SCINT, Alushta, 2005. Edited by A. Gektin, B. Grinyov (2006), pp. 212215.

34. O. Chukova, S. Nedilko, V. Scherbatskyi. Luminescent spectroscopy of lead tungstate crystals doped with europium ions. Phys. Stat. Sol. (c) 4, 8970 (2007).

35. M.U. Bilyi, M. Diab, L.M. Limarenko, Z.T. Moroz, S.G. Nedilko, M.V. Pashkovskyi. Energies of electron states of $\mathrm{Dy}^{3+}, \mathrm{Sm}^{3+}$ and $\mathrm{Pr}^{3+}$ impurity ions in the lead and cadmium tungstate crystals. Ukr. J. Phys. 43, 864 (1998).

36. A. Nosenko, L. Kostyk, L. Koslovska. Some peculiarities of the luminescence of the lead tungstate crystals. J. Lumin. 90, 49 (2000).

37. P.A.M. Berdowski, J. Van Keulen, G. Blasse. Luminescence and energy migration characteristics of $\mathrm{EuWO}_{4} \mathrm{Cl}$. J. Solid State Chem. 63, 284 (1986).

38. O. Chukova, S. Nedilko, V. Scherbatskyi. Luminescent spectroscopy and structure of centers of the impurity $\mathrm{Eu}^{3+}$ ions in lead tungstate crystals. J. Lumin. 130, 1805 (2010).

39. Y. Huang, K.H. Jang, K. Jang, H.J. Seo. Luminescence spectra of $\mathrm{Eu}^{3+}$ ions and interstitial oxygen in $\mathrm{PbWO}_{4}$ crystal. Physica B 403, 75 (2008).

40. Y. Huang, H.J. Seo. Multisite structure of $\mathrm{PbWO}_{4}: \mathrm{Eu}^{3+}$ crystals investigated by site-selective laser-excitation spectroscopy. J. Phys. Chem. A 113, 5317 (2009).

41. S. Burachas, S. Beloglovsky, I. Makov, Yu. Saveliev, N. Vassilieva, M. Ippolitov, V. Manko, S. Nikulin, A. Vassiliev, A. Apanasenko, G. Tamulaitis. Phase transition influence on characteristics of $\mathrm{PbWO}_{4}$ scintillators. Functional Materials 9, 297 (2002).

42. S. Burachas, S. Beloglovsky, I. Makov, Y. Saveliev, M. Ippolitov, V. Manko, S. Nikulin, A. Nyanin, A. Vassiliev, A. Apanasenko, G. Tamulaitis. Influence of variable tungsten valency on optical transmittance and radiation hardness of lead tungstate (PWO) scintillation crystals. Nucl. Instrum. Methods Phys. Res. A 505, 656 (2003).

43. W. Li, X. Feng, Y. Huang. Effects of Cr doping on the optical characteristics of $\mathrm{PbWO}_{4}$ crystals. J. Lumin. 113, 109 (2005).

44. T.T. Basiev, V.N. Baumer, Yu.N. Gorobets, M.E. Doroshenko, M.B. Kosmyna, B.P. Nazarenko, V.V. Osiko, V.M. Puzikov. Peculiarities of the growth of $\mathrm{PbWO}_{4}: \mathrm{Nd}^{3+}$ and $\mathrm{PbMoO}_{4}: \mathrm{Nd}^{3+}$ single crystals. Crystallography Reports 54, 697 (2009).

45. W. Li, Y. Huang, X. Feng. The effects of Nd impurity on the optical, dielectric and electrical properties of $\mathrm{PbWO}_{4}$ single crystals. Phys. Stat. Sol. (a) 202, 2531 (2005).

46. M. Bohm, A. Hofstaetter, M. Luh, B.K. Meyer, A. Sharmann, M.V. Korzhik, O.V. Kondratiev, A.E. Borisevich,

ISSN 2071-0194. Ukr. J. Phys. 2019. Vol. 64, No. 9 
V.V. Laguta, P. Lecoq, E. Auffray. Thermally stimulated luminescence properties of lead tungstate crystals. In: Proceedings of SCINT'99 Conference. Edited by V. Mikhailin (Moscow State University Press, 2000), pp. 619-626.

47. V.V. Laguta, M. Martini, A. Vedda, M. Nikl, E. Mihokova, P. Bohacek, J. Rosa. Photoinduced $\mathrm{Pb}^{+}$center in $\mathrm{PbWO}_{4}$ : Electron spin resonance and thermally stimulated luminescence study. Phys. Rev. B 64, 165102 (2001).

48. J.A. Groenink, H. Binsma. Electrical conductivity and defect chemistry of $\mathrm{PbMoO}_{4}$ and $\mathrm{PbWO}_{4}$. J. Solid State Chem. 29, 227 (1979).

49. A.N. Annenkov, E. Auffray, M.V. Korzhik, P. Lecoq J.P. Peigneux. On the origin of the transmission damage in lead tungstate crystals under irradiation. Phys. Stat. Sol. (a) 170, 47 (1998).

50. C. Yang, G. Chen, P. Shi. Effect of lead vaporization in growth process on the luminescence property of $\mathrm{PbWO}_{4}$ crystal. J. Lumin. 93, 249 (2001).

51. O. Chukova, S. Nedilko, V. Scherbatskyi. Effect of annealing on luminescence properties of the undoped and rare earth doped lead tungstate crystals. Optical Materials 34, 2071 (2012)

52. S. Nedilko, O. Chukova. Study of effects of rare earth impurities on structure of matrix emission of the lead tungstate crystals. IEEE Xplore, Conf. Proc. 6912376: Intern. Conf. on Oxide Materials for Electronic Engineering - fabrication properties and applications, 2014.

53. L. van Pieterson, M. Heeroma, E. de Heer, A. Meijerink. Charge transfer luminescence of $\mathrm{Yb}^{3+}$. J. Lumin. 91, 177 (2000).

54. I.A. Kamenskikh, N. Guerassimova, C. Dujardin, N. Garnier, G. Ledoux, C. Pedrini, M. Kirm, A. Petrosyan, D. Spassky. Charge transfer fluorescence and $f$ - $f$ luminescence in ytterbium compounds. Optical Materials 24, 267 (2003).

55. Y. Huang, X. Feng, W. Zhu. Thermal annealing behavior of luminescence of $\mathrm{Gd}^{3+}$-doped $\mathrm{PbWO}_{4}$ single crystal in air atmosphere. Appl. Phys. A 80, 409 (2005).
56. S. Nedilko, O. Chukova. Luminescent spectroscopy of the $\mathrm{Yb}^{3+}$ ions in the $\mathrm{PbWO}_{4}$ crystal. Acta Phys. Polon. 133, 918(2018).

57. M. Fujita, M. Itoh, H. Mitani, Sangeeta, M. Tyagi. Exciton transition and electronic structure of $\mathrm{PbMoO}_{4}$ crystals studied by polarized light. Phys. Stat. Sol. (b) 247, 405 (2010).

58. P. Lecoq, I. Dafinei, E. Auffray, M. Schneegans, M.V. Korzhik, O.V. Missevitch, V.B. Pavlenko, A.A. Fedorov, A.N. Annenkov, V.L. Kostylev, V.D. Ligun. Lead tungstate $\left(\mathrm{PbWO}_{4}\right)$ scintillators for LHC EM calorimetry. $\mathrm{Nucl}$. Instrum. Methods Phys. Res. A 365, 291 (1995).

59. M. Itoh, H. Yokota, M. Horimoto, M. Fujita, Y. Usuki. Urbach Rule in $\mathrm{PbWO}_{4}$. Phys. Stat. Sol. (b) 231, 595 (2002).

Received 25.07.19

О. Чукова, С. Неділъко

СТРУКТУРА ЦЕНТРІВ МАТРИЧНОГО

СВІЧЕННЯ У БЕЗДОМІШКОВИХ І ЛЕГОВАНИХ

ІОНАМИ РЗЕ КРИСТАЛАХ ВОЛЬФРАМАТУ СВИНЦЮ ТИПУ ШЕЕЛІТУ

$\mathrm{P}$ е $з$ ю м е

Стаття присвячена дослідженню структури центрів люмінесценції кристалів $\mathrm{PbWO}_{4}$ (PWO). Для отримання додаткової інформації про склад спектрів випромінювання матриці РWO та структури їі центрів люмінесценції було використано зразки з домішками рідкісноземельних елементів (РЗЕ). Проведений розклад спектрів випромінювання на окремі смуги показав, що при $10 \mathrm{~K}$ загальні спектри всіх нелегованих і РЗЕ-легованих зразків складаються із 5 смуг. Максимуми отриманих смуг становлять 1,95, 2,2, 2,45, 2,7, 3,0 еВ. Розглянуто вплив РЗЕ-легування та відпалу на відносні інтенсивності цих смуг. Обговорюється природа люмінесценції та структури центрів, що беруть участь у процесах збудження та випромінювання, які відповідають за кожну з виділених смуг. 